\title{
Photobiocatalysis in Continuous Flow
}

\author{
Santiago Nahuel Chanquia ${ }^{1}$, Alessia Valotta ${ }^{2}$, Heidrun Gruber-Woelfler ${ }^{2}$ and Selin Kara ${ }^{1,3 *}$ \\ ${ }^{1}$ Biocatalysis and Bioprocessing Group, Department of Biological and Chemical Engineering, Aarhus University, Aarhus, \\ Denmark, ${ }^{2}$ Institute of Process and Particle Engineering, Graz University of Technology, Graz, Austria, ${ }^{3}$ Institute of Technical \\ Chemistry, Leibniz University Hannover, Hannover, Germany
}

In the last years, there were two fields that experienced an astonishing growth within the biocatalysis community: photobiocatalysis and applications of flow technology to catalytic processes. Therefore, it is not a surprise that the combination of these two research areas also gave place to several recent interesting articles. However, to the best of our knowledge, no review article covering these advances was published so far. Within this review, we present recent and very recent developments in the field of photobiocatalysis in continuous flow, we discuss several different practical applications and features of state-of-the art photobioreactors and lastly, we present some future perspectives in the field.

Keywords: continuous processing, microalgae, photoenzyme, photobioreactors, photobiocatalysis, flow biocatalysis

OPEN ACCESS

Edited by:

Juan M. Bolivar,

Complutense University of Madrid,

Spain

Reviewed by:

Pedro Fernandes,

University of Lisbon, Portugal

Marco P. C. Marques,

University College London,

United Kingdom

${ }^{*}$ Correspondence:

Selin Kara

selin.kara@bce.au.dk

Specialty section: This article was submitted to Biocatalysis,

a section of the journal

Frontiers in Catalysis

Received: 16 November 2021

Accepted: 17 December 2021

Published: 10 January 2022

Citation:

Chanquia SN, Valotta A Gruber-Woelfler H and Kara S (2022) Photobiocatalysis in Continuous Flow.

Front. Catal. 1:816538.

doi: 10.3389/fctls.2021.816538

\section{INTRODUCTION}

\section{Photobiocatalysis}

Even though sunlight has always been at our disposal as a natural, clean, and abundant source of energy and (of course) light, only in recent years the use of light has been fully incorporated as a tool for chemical reactions and lab processes. Since sunlight intensity changes with the weather, the seasons, and also depends on the latitude, artificial sources of light are needed. However, as nowadays we can obtain light from sustainable energy sources, it seems to be an optimal reagent for environmentally friendly chemical processes (Yoon et al., 2010). Fortunately, and thanks to the hard work of many research groups which paved the way for the application of transition metal complexes, organic dyes, natural pigments and nanostructured semiconductors, that allow to collect energy from the visible part of the electromagnetic spectrum, photo- and photoredox catalysis have both experienced a remarkable growth in the last years.

Some impressive results have been achieved, such as an extended substrate scope, and the possibility of working under milder conditions when compared to the light-independent alternatives (Schmermund et al., 2019; Buglioni et al., 2021; López-Vidal et al., 2021; Özgen et al., 2021). Recent noteworthy examples of it are the combination of visible light photoredox catalysis with gold complexes (Hopkinson et al., 2016), the use of porous $\mathrm{Ni}_{5} \mathrm{P}_{4}$ to accelerate photocatalytic hydrogen evolution reaction (HER) (Liu et al., 2020), and the use of co-catalysts in $\mathrm{TiO}_{2}$ photocatalysis (Meng et al., 2019). As seen in these examples, the use of dual catalytic systems is a very interesting approach; therefore, it is not surprising that the combination of photo- and biocatalysis is also a topic of increasing importance. This combination led to the development of improved sustainable synthetic pathways in which light can be a useful tool to produce and/or regenerate cofactors or cosubstrates in situ, powering (chemo)enzymatic cascades (Meyer et al., 2021).

However, while biotransformations have been widely investigated and recognized as sustainable tool to synthetic chemistry for the past 20 years, the combination of photo- and biocatalysis has only recently gathered the interest of the scientific community (Schmermund et al., 2019). Photobioreactions can be categorized into two different groups: in vitro and in vivo. Similarly, in 
the first category we can distinguish two different types, those in which the substrate is photochemically excited and then the reaction proceeds, catalyzed by the biocatalyst, and those in which the biocatalyst is carried to an excited state, directly or indirectly, forming the "active" biocatalyst (Hong, 2020; Meyer et al., 2021). In order to get to this "active" state, photosensitizers or photomediators are excited by light, which means that their electrons are promoted to the lowest unoccupied molecular orbital (LUMO). This enables the indirect regeneration of an enzymatic cofactor through a sacrificial electron donor, the direct transfer of electrons to a prosthetic group of the enzyme, or the indirect transfer of electrons to the enzyme through a mediator (Maciá Agulló et al., 2015; Lee J.-C. et al., 2018). So far, only four types of light-driven enzymes are known, the photosystem I and II (Chitnis, 2001; Vinyard et al., 2013; Barber, 2016), photolyases (Sancar, 2003; Sancar, 2016), protochlorophyllide-reductases (Schoefs and Franck, 2003; Schmermund et al., 2020), and photodecarboxylases (Sorigué et al., 2017). Unfortunately, the first three mentioned enzymes still do not have wide applications in biocatalysis (Scrutton, 2017). On the other hand, the recently discovered photodecarboxylase shows promising results for its application in the production of drop-in fuels via decarboxylation of fatty acids, which are present in natural fats and oils, using blue light (Huijbers et al., 2018; Santner et al., 2021). Despite being an interesting field; it should be taken into account that, in comparison to the application of other fields of photobiocatalysis, the use of photoenzymes is still in its infancy (Björn, 2018).

Even though the photochemical activation of enzymes and the photochemical regeneration of cofactors are elegant methods, there are still many challenges related to their application, such as the generation of highly reactive free radicals, low total turnover numbers (TTNs), and low turnover frequencies (TOFs) of the photocatalyst (Hollmann et al., 2010; Schmermund et al., 2019). These issues can be addressed using different photosensitizers or applying enzyme engineering, but this could be cost-intensive and, in some cases, not practical or efficient. As an alternative that do not present these issues, in vivo photobiocatalysis, for example using autotrophic organisms such as microalgae or cyanobacteria, is very attractive for its application in the synthesis of several different compounds. The photosystem present in these microorganisms, which enables the process of photosynthesis, converts light into redox equivalents while the cell itself provides specialized electron transport chains, controls reactive species such as radicals, and regenerates the system in case of damage. Usually, biotransformations carried out using microalgae are highly selective, have good atom economy, and allow the design of systems for cofactor regeneration (Schmermund et al., 2019). But there are also challenges related to in vivo photobiocatalysis, associated with its upscaling, and the difficulty in standardizing processes, since different organisms require diverse conditions, and usually the cultures are very sensitive to changes in temperature, salinity, $\mathrm{pH}$, light intensity, nutrient concentration and agitation (Yen et al., 2019).

\section{Photo(bio)reactor Technology}

The most common way to grow microorganisms for photobiotransformations is using open photobioreactor (PBR) systems, which are economical in terms of construction, operation and maintenance, but have a poor control on growth conditions, which makes them inadequate for the production of fine chemicals (Chisti, 2007; Chanquia et al., 2021). These PBRs are usually raceway-shaped shallow pools. Conversely, closed PBRs rise as an alternative that has attracted a great deal of attention in the last years. They demand a higher initial investment, and also the costs related to their operation and maintenance are higher than those of open systems; however, they offer an excellent control over cultivation conditions, which usually results in better productivities (Zhu et al., 2018). Closed PBRs can have many different configurations and shapes, being horizontal or vertical tubular vessels, flat panels or even plastic bags, just to mention some of the most common (Chanquia et al., 2020; Chanquia et al., 2021).

On the other hand, continuous flow reactors have been thoroughly studied in the last 2 decades, but especially in the last years this discipline has experienced a sharp increase in the number of publications, as seen in Figure 1, with several different reported applications of this technology, and a special emphasis in miniaturized flow reactors and also in carrying out reactions that underperform in batch (Valera et al., 2010; Plutschack et al., 2017; De Santis et al., 2020). This is not a surprise if we consider the many advantages that flow systems present over batch ones, especially when considering microscale reactors (Bolivar et al., 2011; Žnidaršič-Plazl, 2021a; Žnidaršič-Plazl, 2021b). Amongst these advantages we must mention that they are adequate for processes involving heterogeneous catalysis, such as those using immobilized enzymes (Gkantzou et al., 2018; Thompson et al., 2018), they have very fast mixing and heat exchange rate (Hartman et al., 2011; Gürsel et al., 2015; Cambie et al., 2016), large interfacial area when dealing with multiphase systems (Noël and Hessel, 2013; Mallia and Baxendale, 2016), improved reaction selectivity and reproducibility (Hartman et al., 2011; Talla et al., 2015; Cambie et al., 2016), simplified or even automated downstream processing (Webb and Jamison, 2010; Pastre et al., 2013; Fabry et al., 2014; Ley et al., 2015; Fabry et al., 2016), increased operational safety (Gutmann et al., 2015; Cambie et al., 2016) and, in the case of photoreactions, a reliable scale-up and an improved irradiation of the reaction mixture (Geyer et al., 2006; Wegner et al., 2011; Su et al., 2014; Su et al., 2016).

There are many excellent recent reviews focusing on continuous flow chemistry, continuous flow photocatalysis and photobiocatalysis in general, but to the best of our knowledge, there are no articles giving an overview of the recent advances in the combination of these disciplines, which is "photobiocatalysis in flow." Amongst these reviews we want to highlight the publications made by Schmermund et al. (2019), that gives an overview on the different possible strategies for using light in biocatalysis, and Meyer et al. (2021), which covers the most recent advances regarding in vitro photobiocatalysis. Additionally, Chanquia et al. (2021) describes different photobioreactors setups, as well as challenges and perspectives related to them. On the other hand, we also believe that is important to mention the publications by Özgen et al. (2021), that focuses on how to overcome challenges when dealing with photo(chemo) enzymatic reactions, and Seel and Gulder (2019) who reviewed 


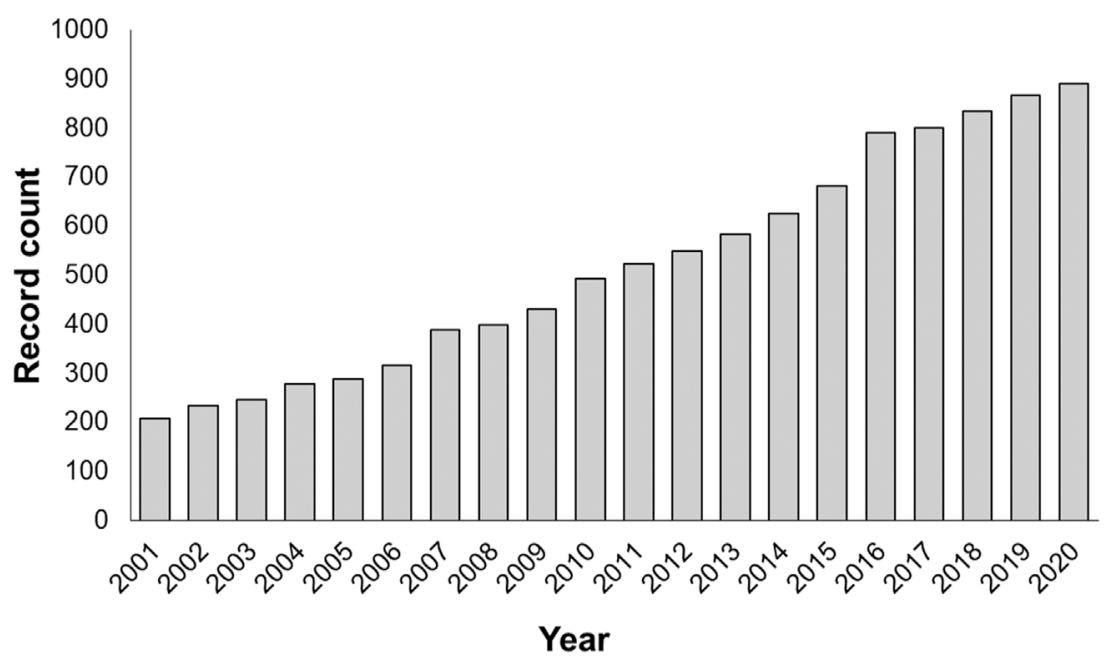

FIGURE 1 | Number of relevant publications in the period 2001-2020 in which it is possible to see the growing interest in the application of continuous flow strategies. Analysis made using "Web of Science" database searching "continuous flow reactors" as topic on the 11-08-2021.

several different relevant photocatalyzed transformations. On the field of continuous flow chemistry and photochemistry, we consider especially noteworthy the works made by Plutschack et al. (2017), who wrote an astonishing guide for flow chemistry, the thorough review made by Buglioni et al. (2021), covering the latest innovations in photochemistry applied in organic synthesis, the recent work by De Santis et al. (2020), that reviews very recent developments of biocatalysis in flow, the work by Britton et al. (2018) with an interesting overview of immobilization methods for the synthesis of different products, and the review made by Cambie et al. (2016), that focuses on the applications of continuous flow photochemistry in organic synthesis, material science and water treatment. Additionally, a very recent study from Žnidaršič-Plazl (2021b) gives an overview on heterogenization of enzymes, miniaturization of processes and process integration.

This review aims to fill a gap that it is present in the current literature, covering some of the latest advances and the state-ofthe-art of photobiocatalytic reactions in continuous flow in a concise and straightforward way, as well as the most important features and possible improvements for the different reactors used to carry out these processes. Moreover, an outline on the design and optimization principles of flow photocatalytic reactors will be presented, with the goal of providing some general guidelines to facilitate the transition of photobiocatalysis from batch to flow.

\section{FLOW PHOTOBIOCATALYSIS}

In this section, the latest applications of flow photobiocatalysis in selected key research fields, such as 1) organic synthesis, 2) energy carrier production and 3) environmental biotechnology for air and water treatment will be discussed.

\section{Flow Photobiocatalysis in Organic Synthesis}

Until now, the main research focus of photobiocatalysis in continuous flow has been on in vivo applications. This approach has several advantages, since these biotransformations are highly selective, have good atom economy, and allow designing systems for cofactor regeneration (e.g., NADPH), as shown on Figure 2 (Köninger et al., 2016; Özgen et al., 2021).

In this field, the number of studies regarding production of biofuels using phototrophic organisms has been increasingly growing in the last years (Sero et al., 2020) and, even though most of them have covered batch photobioreactors, there are some interesting examples regarding flow cultivation of microalgae and production of lipids. A review published by Fernandes et al. (2015) covers approaches and applications of continuous cultivation of phototrophic organisms, whereas an article by Remmers et al. (2017) quantitatively compares continuous versus batch production of lipids in a Acutodesmus obliquus culture. In this last case, the authors conclude that batchwise operation is the preferred cultivation strategy. Also (Dasan et al., 2020), have recently developed a sequential-flow system using several batch photobioreactors for the cultivation of Chlorella vulgaris, which enhances the growth of the microalgae and the $\mathrm{CO}_{2}$ fixation efficiency since it increases the retention time. This system consists of four bubble column photobioreactors connected in series by a continuous flow of atmospheric air and it proved to be a good option for carbon capture. Furthermore, when the microalgae were cultivated in recycled medium the lipid accumulation increased and they obtained fatty acid methyl esters (FAMEs) of good quality, which could be used as biofuels.

With the aim of enabling the high density cultivation of phototrophic organisms, which is a condition for the upscaling 


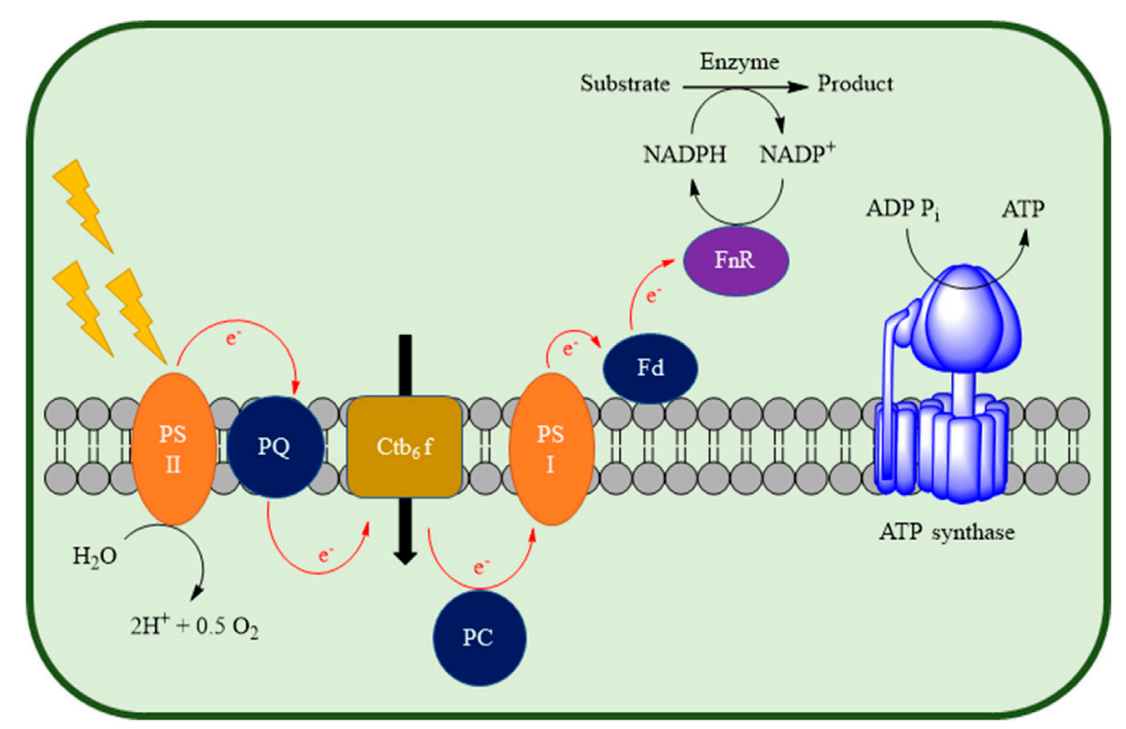

FIGURE 2 | Representation of in vivo photobiocatalytic NADPH regeneration by using the photosystems present inside a phototrophic microorganism's cell, coupled with heterologous oxidoreductases. Ctb6 f: cytochrome b6 f complex, Fd: ferredoxin, FnR: terminal reductase, PC: plastocyanine, PQ: plastoquinone, PSI: photosystem I, PSII: photosystem II. Adapted from Özgen et al. (2021).

of photobioprocesses, Hoschek et al. (2019) have introduced capillary biofilm reactors for the continuous oxidation of cyclohexane to cyclohexanol. The biofilm was composed by the combination of the $\mathrm{O}_{2}$ producing Synechocystis sp., containing a recombinant cyclohexane monooxygenase, with the $\mathrm{O}_{2}$ respiring Pseudomonas taiwanensis. In this way they avoided $\mathrm{O}_{2}$ accumulation in the reactor, which is the main obstacle for the development of industrial-scale photobioprocesses (Vonshak and Torzillo, 2004). Applying this methodology, they achieved a density of 51.8 gbiomass dry weight $\times$ $\mathrm{L}^{-1}$, a productivity of $3.76 \mathrm{~g} \times \mathrm{m}^{-2} \times$ day $^{-1}$ of cyclohexanol for over a month, and a conversion of $98 \%$. These are excellent results, but it should be noted that the total inlet concentration of cyclohexanol for these experiments was relatively low (1 mM).

As mentioned at the beginning of this section, in vivo strategies are the most used in flow photobiocatalysis due to the stability issues that photoenzymes present, and probably also because of the difficulty of adapting a cascade or a cofactor regeneration system to a flow setup. Nevertheless, there are interesting examples of coupled in vitro systems, such as the one published by $\mathrm{Gu}$ et al. (2020), in which they present an integrated process of formate synthesis from $\mathrm{CO}_{2}$. In order to achieve this, they use a hollow fiber membrane immobilized formate dehydrogenase coupled with a $\mathrm{UV} / \mathrm{TiO}_{2}$ photocatalytic NADH regeneration system. Applying this methodology, they achieved an elevated utilization efficiency of the cofactor, and both the initial reaction rate and the production of formate was multiplied several times.

\section{Flow Photobiocatalysis for $\mathbf{H}_{2}$ Synthesis}

Amidst the different alternatives that are studied to replace or at least decrease the use of fossil fuels, $\mathrm{H}_{2}$ is a very promising clean energy carrier, since its combustion generates no pollutants and also produces large amounts of energy $\left(143 \mathrm{GJ} \times\right.$ tonne $^{-1}$ ) (Kayahan et al., 2017; Bolatkhan et al., 2019). Paradoxically, currently around $98 \%$ of industrial production of $\mathrm{H}_{2}$ is derived from non-renewable sources (Muradov, 2017), which shows the urgent need of an alternative for the production of $\mathrm{H}_{2}$, which would be an important step towards a circular sustainable economy. In this context, the photofermentative production of $\mathrm{H}_{2}$ by phototrophic organisms shows great potential, since they can produce hydrogen from organic substances using only (solar) light (Sağır et al., 2018).

Recently, Wang et al. (2019) used a flat panel PBR with a polymethyl methacrylate grid columnar, in which they have grown a Rhodopseudomonas palustris biofilm for the continuous flow photofermentative production of $\mathrm{H}_{2}$. Using this setup under optimized conditions, the authors report a maximum hydrogen production rate of $32.6 \mathrm{mmol} \times \mathrm{L}^{-1} \times$ $\mathrm{d}^{-1}$, which is roughly three times higher than that reported in previous literature (Zhang et al., 2010), and a hydrogen yield of $1.15 \mathrm{~mol} \mathrm{H}_{2} \times$ mol glucose ${ }^{-1}$. It is also interesting to mention some of the features of the reactor they used, such as the modification of the column surfaces with silane, which increased their hydrophobicity, improving the cell attachment rate in the reactor. Zhang et al. (2019) have also worked on continuous sustainable hydrogen production, in this case by developing an alveolar flat panel PBR for Rhodopseudomonas palustris biofilm formation, reporting an $\mathrm{H}_{2}$ mean yield of $1.8 \mathrm{~mol}$ $\mathrm{H}_{2} \times$ mol glucose ${ }^{-1}$.

More recently, Jiang et al. (2020) used corn stark pith hydrolysate as a substrate, which is a very low cost organic material, and a photosynthetic consortium consisting of five bacterial strains (Rhodospirillum rubrum, Rhodopseudomonas capsulata, Rhodopseudomonas pulastris, Rhodobacter sphaeroides, and Rhodobacter capsulatus) isolated from silt 
sewage, pig manure and cow dung as the inoculum for the continuous photofermentative production of $\mathrm{H}_{2}$ in a selfdesigned long tubular PBR. They reported a maximum hydrogen production rate of $37 \mathrm{mmol} \times \mathrm{L}^{-1} \times \mathrm{d}^{-1}$ after $24 \mathrm{~h}$ at $30^{\circ} \mathrm{C}$.

\section{Flow Photobiocatalysis in Air and Water Treatment}

Wastewater generation and atmospheric pollution have become two of the biggest environmental concerns in the last decades, and urgent measures are needed to decrease the impact they have on our planet, with terrible consequences such as eutrophication of aquatic environments, acid rain, depletion of $\mathrm{O}_{3}$ in the stratosphere, and global warming amongst others (Mudliar et al., 2010; Mathur and Balomajumder, 2013; Choudhary et al., 2016; Sánchez-Morales et al., 2018).

In this context, Oliva et al. (2019) studied a novel bacterial LED-illuminated tubular $\mathrm{PBR}$ and compared it with a conventional biotrickling filter for the continuous abatement of toluene, which was chosen as a model volatile organic compound. In this study they used an activated sludge, consisting of both microalgae and bacteria, from a wastewater treatment plant as inoculum for both PBRs. The average removal efficiency was $86 \pm 9 \%$, which is very similar to a conventional biotrickling filter, which they also evaluated. The advantage of their approach is that the conventional filter resulted to be more sensitive towards the accumulation of secondary inhibitory metabolites, which significantly affect the process performance. This approach shows that the synergism between these two different microorganism types could be used for the biodegradation of volatile compounds and $\mathrm{CO}_{2}$ fixation.

Regarding the treatment of water (Lee S. H. et al., 2018), have used a submerged membrane photobioreactor working under a semi-continuous regime for the treatment of livestock wastewater with excellent removal efficiency of nitrogen (96\%) and phosphorus $(85 \%)$, and a generated biomass concentration up to $3,500 \mathrm{mg} \times \mathrm{L}^{-1}$ (dry weight). More recently, Sánchez-Contreras et al. (2021) investigated the capacity of a mixed microalgae culture to remove organic substrates from industrial effluents while simultaneously producing carbohydrate-rich biomass in a semi-continuous stirred tank PBR. In this case they report removal efficiencies up to $72 \%$ of nitrogen and $100 \%$ of phosphorus, while achieving a maximum production of $0.033 \mathrm{~g} \mathrm{~L}^{-1} \times \mathrm{d}^{-1}$ of biomass.

\section{PHOTOBIOREACTORS FOR APPLICATIONS IN CONTINUOUS FLOW}

Photobioreactor (PBR) design and optimization is a major aspect of photobiochemical processes, being the light provision to the reactors one of the major challenges, since it decreases exponentially with the distance from the light source in batch (see Figure 3). In this aspect, continuous flow processes have an edge, since light penetration is uniform regardless of the reactor scale (Cambie et al., 2016; Loubiere et al., 2016). However, while

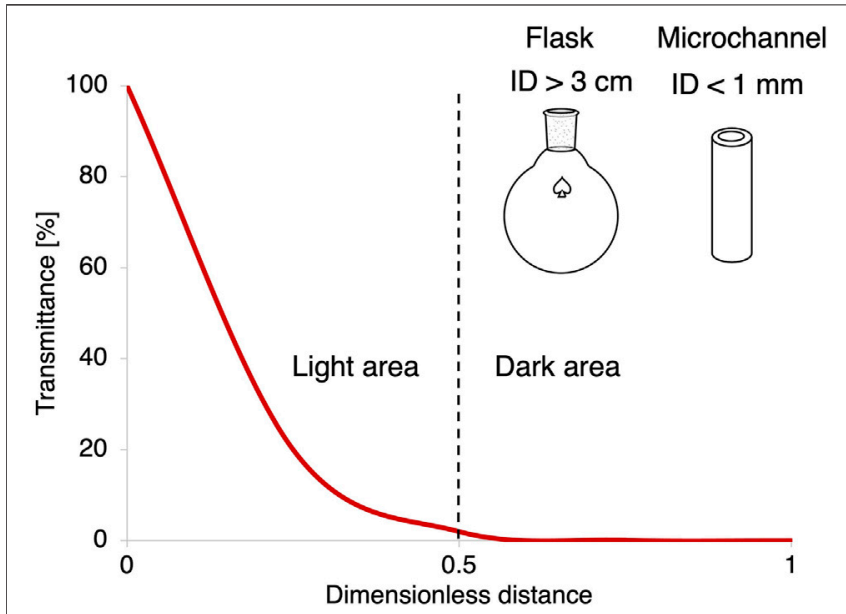

FIGURE 3 | Plot of the light transmittance as a function of the dimensionless distance from the light source, according to the Lambert-Beer correlation.

numerous reviews are available for the design of continuously operated photobioreactors for microbial cell growth and photofermentative processes (Adessi and De Philippis, 2014; Zhou et al., 2015; Yen et al., 2019) very little information is available on how to design a reactor for photobiocatalytic purposes, especially for continuous flow applications. Nevertheless, there are some examples of novel reactor designs for photocatalytic reactions in flow reported in literature that have the potential to be applied in biocatalysis (Visan et al., 2019; Sambiagio and Noël, 2020; Sundar and Kanmani, 2020).

\section{Reactor Design and Process Optimization}

The starting point for the PBR design is to study the kinetics of the photobiocatalytic reaction of interest. This is a general principle for any reactor design approach, as knowing the reaction kinetics allows to choose the appropriate reactor geometry and volume to achieve the desired conversion. In the case of a photobiocatalytic process, this means that in a first phase it would be necessary to determine the kinetic parameters in batch (such as the MichaelisMenten parameters) in order to have an estimate of the characteristic reaction time. For photochemical reactions, these parameters do not just depend on the reactant concentration or the reaction rate, but also on the intensity of the incident beam of light that is fueling the photocatalytic process. Therefore, both the effect of the light wavelength and intensity on the reaction should be investigated. The optimal light intensity generally lies in a specific range, since increasing the light intensity could speed up the reaction; however, passing a certain limit could induce light stress in phototrophic organisms, inactivate photoenzymes or cause early bleaching of the photocatalyst (Assil-Companioni et al., 2020; Lakavath et al., 2020). The light source should also be chosen in a way to deliver these optimal values while keeping the energy consumption low.

A typical flow photocatalytic setup is shown in Figure 4, including its main parts, namely mixing, reaction, and quenching units (Su et al., 2014). Furthermore, inline sensors implemented 


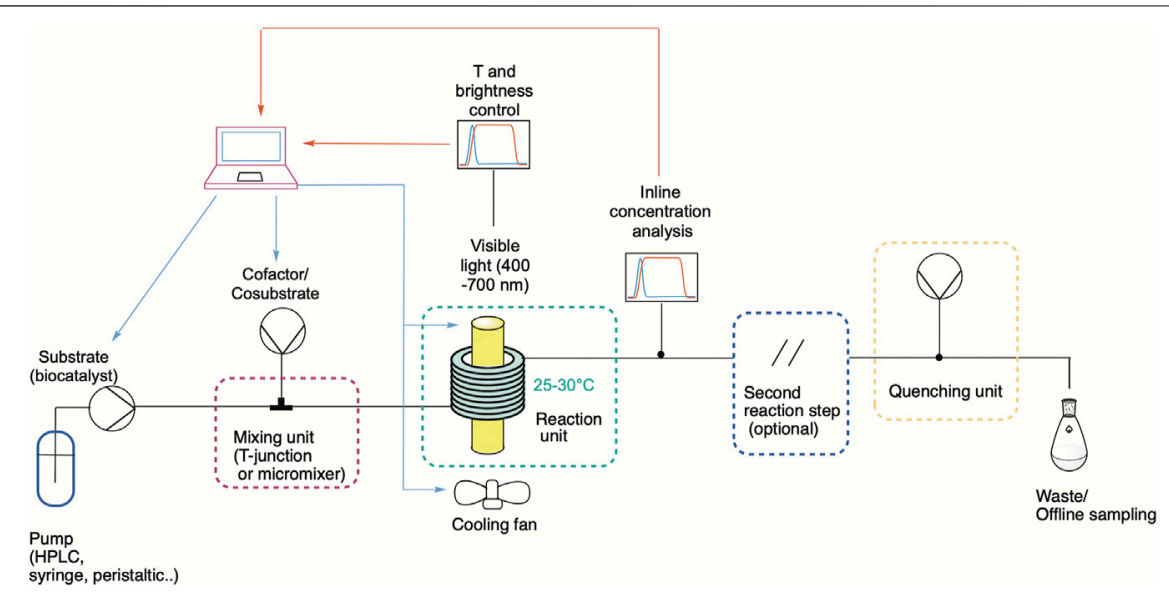

FIGURE 4 | Typical flow setup for photocatalytic applications. Two or more pumps are used to introduce the starting materials (including the biocatalyst if it is used in solution) into the mixing unit, where they are properly homogenized before entering the photoreactor. There, the reaction occurs under light of an optimal wavelength and intensity, which ideally can be controlled and set remotely via a PC or microcontroller. The temperature can also be monitored by commercially available sensors, connected for example to a cooling fan to reduce the temperature rise due to the lamp's heat dissipation. At the outlet, the outcome of the reaction can be monitored in real-time via inline analytics. Optionally, a second step can be coupled, e.g., further reaction or purification steps. Finally, the reaction can be quenched before the stream goes to waste or further sampling.

TABLE 1 | List of relevant parameters for the design and optimization of PBR.

\section{Parameter}

Reaction kinetics

Wavelength of light

Incident light intensity

Residence time $(\tau)$

Space-time-yield (STY)

Photocatalytic STY (PSTY)

Quantum yield $(\phi)$

Specific activity

\section{Description}

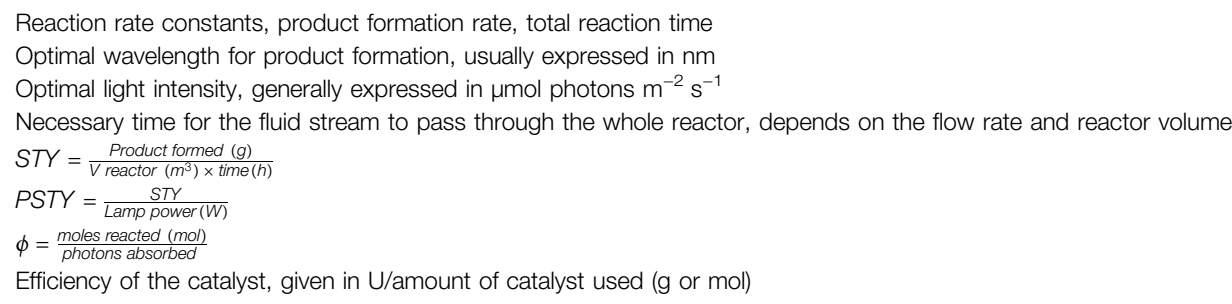

inside the reactor or using flow cells at the output of the reactor should be considered when designing a continuous process. Using this approach, real-time measurement and monitoring of the critical process parameters are feasible. The design principles for photocatalytic processes in continuous flow can be translated to PBRs if the bioprocess characteristics and parameters are carefully assessed. Some of the most relevant parameters for PBR design and optimization are presented in Table 1 and will be discussed in the following sections.

\section{Choice of Light Source}

Regarding the possible visible light sources and their characteristics (see Table 2), it is possible to list four alternatives, each with their pros and cons. 1) Compact fluorescent lights have been widely used in photochemistry due to their low cost and high availability; however, they have a short lifetime, they are highly energy-demanding, and dissipate heat. 2) Lasers provide a high-power source of light; however, they are too bulky and expensive. 3) Sunlight seems to be the best choice, being low cost, greatly available and sustainable; however, it has a highly fluctuating irradiance, which makes it difficult to use it as a continuous source of light and is not very practical on lab scale. 4) Light emitting diodes (LEDs) have been appointed as an optimal solution due to their high light intensity and low heat dissipation, but unfortunately their price is still prohibitive in some cases (Su et al., 2014). Grogan et al. (2019) have enumerated the criteria that a PBR using LED as light source should satisfy regarding illumination: 1 ) The system must be flexible regarding its scalability using a single light source, 2) the light intensity must be variable to be able to understand the optical power requirements of the process, 3) the PBR should have a powerful cooling system, so that photochemical and thermal processes can be decoupled, and lastly, 4) the LEDs must be monochromatic so that the wavelength used for the biotransformation can be identified. An interesting approach regarding wavelength optimization has been recently published by Winkler et al. (2021), in which they use a custom-made multichannel PBR to evaluate several wavelengths at the same time for the photodecarboxylation of palmitic acid using Chlorella variabilis photodecarboxylase. Another interesting approach regarding light conditions has been performed by Baer et al. (2016), in which they evaluated different red-green- 
TABLE 2 | Comparison of different visible light sources available for photo(bio)catalysis (adapted from Su et al., 2014).

\begin{tabular}{|c|c|c|c|}
\hline Light source & Emission wavelength & Advantages & Disadvantages \\
\hline Compact fluorescent lamp (CFL), high pressure Hg & Continuous between $360-600 \mathrm{~nm}$ & Low cost, high availability & Inefficient, short lifetime, heat dissipation \\
\hline Vis-LED & $400-700 \mathrm{~nm}$ & $\begin{array}{l}\text { Compact and adaptable } \\
\text { Low cost and energy input }\end{array}$ & Expensive if high power is needed \\
\hline Laser & Discrete wavelengths & High intensity & Expensive, large \\
\hline Sunlight & $5 \%$ UV, $43 \%$ Vis, $52 \%$ NIR & Cheap source & Variable irradiance \\
\hline
\end{tabular}

blue (RGB) ratios while keeping the overall photon flux density constant for the continuous cultivation of different algae in a bubble column PBR. Also, the light position needs to be optimized in order to allow for optimal irradiation. Generally, the light source is provided externally to the reactor, and a mirror collector can be used to harvest as much light as possible. In this regard, Heining et al. (2015) have proposed an alternative approach where wireless light emitters (WLEs) can be used as internal light source to optimize light absorption in a PBR for cultures of phototrophic microorganisms. In their work, the authors have reported a duplicated growth rate by using WLEs compared to an externally illuminated PBR. Hobisch et al. (2021) have implemented WLEs in a recent work to improve the light distribution and the product formation in a bubble column reactor using cyanobacteria as whole-cell biocatalysts. By using floating WLEs, the product formation rate could be doubled compared to when using an external light source, and specific activities up to $65.5 \mathrm{U} \mathrm{g}_{\text {dry cell weight }}{ }^{-1}$ were obtained. The internal illumination approach would be very interesting and promising also for continuous flow applications, e.g., in a packed bed reactor.

\section{Reactor Material Selection}

Since the light distribution is a crucial parameter for PBR design, it is not only necessary to find the best possible light source, but also to optimize the reactor geometry to allow for a homogeneous light distribution, as well as choosing an ideally transparent material to maximize transmission. One of the most used materials in photocatalytic applications is certainly glass, which is available in many variants according to the desired properties (e.g., cut-off wavelength and chemical resistance). Despite its excellent optical properties, glass is very fragile and very difficult to mold and shape via micromachining, which makes it difficult to use for customized reactors. Polymeric materials are also widely used, such as polymethylmethacrylate (PMMA), polydimethylsiloxane (PDMS), perfluoroalkoxyalkane (PFA), or polytetrafluoroethylene (PTFE). These materials allow for very high transmission, they are cheap and can be easily treated with additive manufacturing techniques to realize customized reactors (Cambie et al., 2016). The chemical resistance is not as high as for glass, however since in biocatalytic applications mostly water-based reaction media are used, this is not an issue. It is also important to consider that the material of choice should be chemically inert and the compatibility with the biocatalyst should be assessed, as the leaching of the reactor material into the reaction solution may reduce enzyme activity and/or stability.

\section{Form of the Biocatalyst Preparation}

Another crucial parameter to take into consideration in the PBR design would be the form of the catalyst, namely if it is used free or immobilized. Using the free biocatalyst avoids mass transfer limitations, however the removal of the biocatalyst from the reaction solution may be not trivial. Therefore, immobilized biocatalysts are often preferred, due to the ease of handling, separation and the possibility of reusing the biocatalyst over numerous cycles. However, in this case mass transfer limitations need to be considered, as well as lower catalytic activities of the immobilized biocatalysts compared to their free forms that might arise due to conformational changes during the immobilization process (Zhu et al., 2020). In biocatalytic flow applications, many progresses have been achieved in the immobilization of both isolated enzymes and whole-cells, which have been summarized in excellent reviews (Kim and Herr, 2013). For continuous flow applications, the most common immobilization methods to this day are 1) covalent or noncovalent binding, either onto particles or on the reactor's surface; and 2) encapsulation in a biocompatible matrix, such as sodium alginate, and carrier-free cross-linking (De Santis et al., 2020). Even some phototrophic organisms have been immobilized, for example for the photofermentative production of $\mathrm{H}_{2}$, with good results in terms of productivity (Tsygankov and Kosourov, 2014). The question remains, if these immobilization technologies could be applied in the future to other type of photobiocatalytic processes, especially in flow reactors, but the immobilization strategy needs to be evaluated case-by-case specifically for the biocatalyst and the process at hand.

\section{Reactor Design}

The next step for bringing the batch process to continuous flow would be to choose the reactor geometry, considering both the evaluated kinetics, the nature of the catalyst (if free or immobilized) and other needs of the process (e.g., how many phases are involved in the reaction). With regards to the reaction kinetics, the reactor should be dimensioned in a way that the available residence time is greater than the characteristic reaction time. The parameter that considers this relation is the so-called "first Damköhler $\left(\mathrm{Da}_{\mathrm{I}}\right)$ " number:

$$
\mathrm{Da}_{\mathrm{I}}=\frac{\tau}{\mathrm{t}_{\mathrm{r}}}
$$

Where " $\tau$ " indicates the residence time inside the reactor and " $\mathrm{t}_{\mathrm{r}}$ " is the reaction time. A $D a_{I}$ greater than 1 ensures that all the components in the reaction volume have enough time to react. 
For tubular reactors or microreactors, the residence time can be easily adjusted by varying the flow rate or the volume of the reactor. The reactor should be also designed to achieve optimal mixing. This implies that the characteristic mixing time needs to be shorter than the reaction time to avoid concentration gradients, which could promote the formation of side products and a decrease of the overall yield. This relation is considered by the "second Damköhler ( $\left.\mathrm{Da}_{\mathrm{II}}\right)$ "number:

$$
\mathrm{Da}_{\mathrm{II}}=\frac{\mathrm{t}_{\mathrm{m}}}{\mathrm{t}_{\mathrm{r}}}
$$

Where " $t_{\mathrm{m}}$ " is the characteristic mixing time, which depends on many different parameters (such as the reactor volume/geometry, stirring speed, flow rate, viscosity of the fluid, and diffusivity of the compounds). For values of $D a_{I I}$ lower than 1 , the process is kinetics-limited, while for $D a_{I I}$ greater than 1 the process is diffusion-limited. The mixing efficiency and $t_{m}$ can either be determined via empirical correlations or experimentally, using colorimetry assays or mixing-sensitive reactions (Kockmann et al., 2006). The mixing behavior in the reactor can be improved by using a higher flow rate or introducing numerous bends and complex channel geometries in the reactor (e.g., split-andrecombine or staggered herringbone structures Hessel et al., 2005), with the purpose of achieving a higher chaotic advection and the formation of secondary flows that promote a higher level of mixing. Another valid solution would be implementing mixing sections before the reactor inlet, e.g., by using micromixers. The mass transfer is especially limiting for multiphasic systems, e.g., in presence of gas/liquid reactions or when using an immobilized biocatalyst. In these cases, it is especially important to improve mixing in order to increase the contact between phases and facilitate the interfacial mass transfer (Kashid et al., 2011). Other dimensionless numbers that are important for the reactor design (e.g., $\mathrm{Da}_{\mathrm{III}}$ and $\mathrm{Da}_{\mathrm{IV}}$ ) or for the characteristic flow behavior ( $\mathrm{Re}$ and $\mathrm{Bo}$ ) will not be discussed in this work as they are not in line in the purpose of this review. However, for the reader that wants to delve deeper into continuous reactor design, we refer to other recommendable works available in literature, such as de Bellefon (2004); Su et al. (2014); Loubiere et al. (2016).

\section{Possible Reactor Geometries}

When it comes to choosing the right reactor geometry for a specific photobiocatalytic application, some examples already used in flow photocatalysis could be adapted to an investigated process (Su et al., 2014; Sambiagio and Noël, 2020). Some typical reactor geometries are depicted in Figure $\mathbf{5}$ and the different characteristic measures are summarized in Table 3. In this review, we do not consider the classic stirred tank reactor due to the poor light distribution, as previously shown in Figure 3. The coil reactor is the easiest and mostly used one in flow photochemistry: It consists of a flexible tube (generally PTFE) wrapped directly around a light source, in order to maximize the irradiated surface. Due to the small channel diameter (generally $<1 \mathrm{~mm}$ ) the light distribution within the reactor is more homogenous than inside a batch reactor, resulting in shorter reaction times and consequently less side-product formation due to over-irradiation, often observed in batch. The catalyst can be either immobilized on the tube walls or pumped through in the reaction solution. The throughput of the reactor can also be easily adjusted by increasing the reactor length. Another type is the packed bed reactor, which is a viable option if the biocatalyst is immobilized on solid particles or entrapped in a matrix (e.g., sodium alginate). It consists of a transparent tube packed with the immobilized biocatalyst. The reactor length and diameter can be sized to accommodate the desired reaction volume; however, the reactor wall needs to be thin and of a transparent material that allows almost $100 \%$ transmission of the incident light. Light distribution can be maximized by using mirror collectors, however the intrinsic problem with a photocatalytic packed bed reactor is still the poor light distribution inside the core section of the tube. In fact, if an external light source is used, the catalyst particles in the core of the reactor might not absorb enough light to catalyze the reaction, resulting in dark areas and a decrease in the overall yield. Moreover, depending on the size of the catalyst, backpressure and mass transfer could be limiting parameters for the overall process efficiency. These drawbacks make photocatalytic packed bed reactors difficult to scale up. A variant of the packed bed reactor that allows for higher illumination efficiency is the annular reactor. In this case the reactor is built in a tube-in-tube mode around a light source, with a chosen active area thickness that allows for optimal light distribution. However, both backpressure and mass transfer can still be an issue, especially if the fluid is not properly distributed along the reactor length. Other two possibilities are the flat plate and the chip-like microreactor. In the first case, the catalyst can be packed between two flat surfaces kept at a fixed (short) distance, while the light source can be placed at the desired distance outside the reactor. This can be also used to maximize the harvested light; however, it might result in high back pressures if the reactor is too tightly packed. However, a homogenous fluid distribution can be achieved by using multiple fluid ports at both ends of the reactor. Finally, the chip microreactor is already an established geometry in flow chemistry, as it can be easily machined with custom-made channel shapes and from transparent materials, such as silicon or PDMS. Such reactor can also be applied to the photobiocatalytic processes, where again the catalyst can be either immobilized or pumped through as a suspension. Moreover, scale-up can be easily carried out by connecting multiple microreactors in parallel, following the so-called numbering up approach.

\section{Process Optimization}

After having chosen the reactor geometry, the main parameter to consider in order to optimize productivity of a given PBR is the space-time-yield (STY), meaning the amount of product formed/ reagent converted over the reactor volume and operating time (see Table 1). The productivity can be increased by improving the mass transfer by ensuring intensive mixing inside the reactor and by optimizing the light distribution to minimize the extent of dark areas. In addition, the flow rate could be increased, given that still enough residence time is provided for the reaction to achieve the 


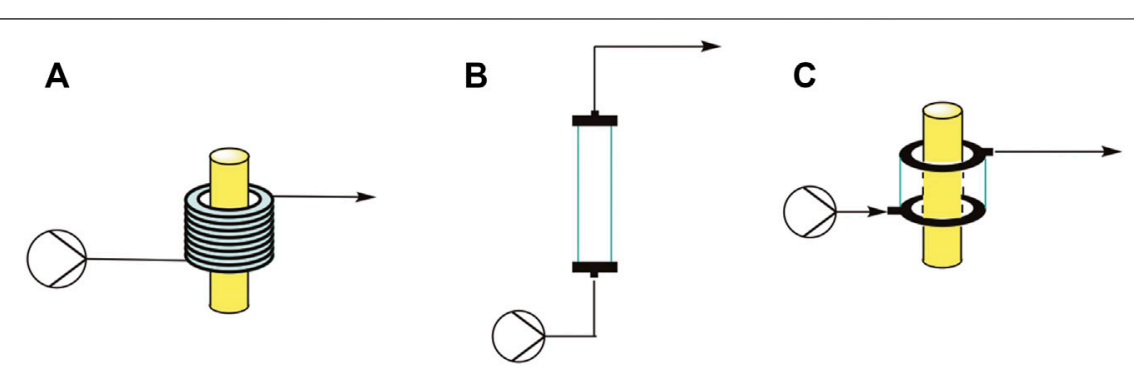

Coil reactor

Packed bed reactor

Annular reactor

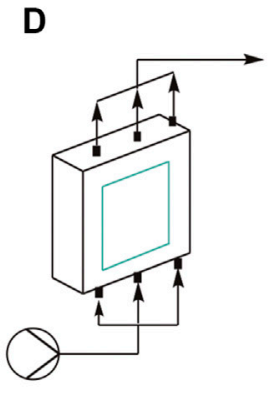

Flat panel reactor

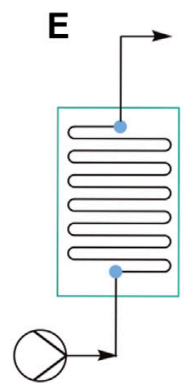

Chip microreactor

FIGURE 5 | Selected photoreactors commonly used in flow photocatalysis that could be applied in photobiocatalytic applications. (A) Coil reactor. (B) Packed bed reactor. (C) Annular reactor. (D) Flat panel reactor. (E) Chip microreactor.

TABLE 3 | List of characteristic measurements for the different reactor geometries presented in this work. For the coil, the surface area/volume ratio was estimated for a coil with length of $1 \mathrm{~m}$ and ID of $1 \mathrm{~mm}$.

\begin{tabular}{|c|c|c|c|}
\hline Reactor type & Characteristic measure & $\begin{array}{l}\text { Surface area/volume } \\
\qquad\left[\mathrm{m}^{2} \times \mathrm{m}^{-3}\right]\end{array}$ & References \\
\hline Coil & $\mathrm{ID}<1 \mathrm{~mm}$ & 4,000 & $(-)$ \\
\hline Packed bed & $\mathrm{ID} \leq 20 \mathrm{~mm}$ & 400 & Zheng et al. (2020) \\
\hline Annular reactor & Thickness $\leq 20 \mathrm{~cm}$ & 50 & Jung et al. (2005) \\
\hline Chip microreactor & $\mathrm{ID}<1 \mathrm{~mm}$ & $10^{4}$ & Hartman et al. (2011) \\
\hline
\end{tabular}

desired yield, or the reactor length can be increased to have a higher processed volume. In the specific case of PBRs, also the photocatalytic space-time-yield (PSTY), meaning the ratio between the STY and the lamp power needs to be optimized. This implies that the energy required to power the lamp needs to be minimized to keep the environmental impact of the process low: therefore, only efficient light sources (such as LEDs) should be used. Also, as mentioned before, the amount of light that is delivered to the process must be maximized to reach a high quantum yield, meaning a high product formed vs. absorbed photons ratio. This can be achieved by finding the optimal light intensity and position, as well as considering the optimal reactor geometry and material to decrease the extent of unabsorbed photons (Sundar and Kanmani, 2020). Also the reaction kinetics needs to be considered, since there could be other reactions in competition with the photochemical transformation of interest or the catalyst could undergo inactivation after a certain time, in both cases the quantum yield would be reduced (Loubiere et al., 2016).

Regarding light harvesting and usage, a recommendable review has been published by Hutton et al. (2017) covering advances about the use of carbon nanodots (CNDs) as photosensitizers for solar-driven catalysis. CNDs have many advantages that makes them very tempting to use as light-harvesters, such as 1) low price, 2) excellent surface to volume area, 3) good photostability and 4) tunable properties. Even though CNDs are starting to be competitive when compared to other photosensitizers, there are still challenges to tackle, such as the short half-life of their excited states, uncertainty in the 


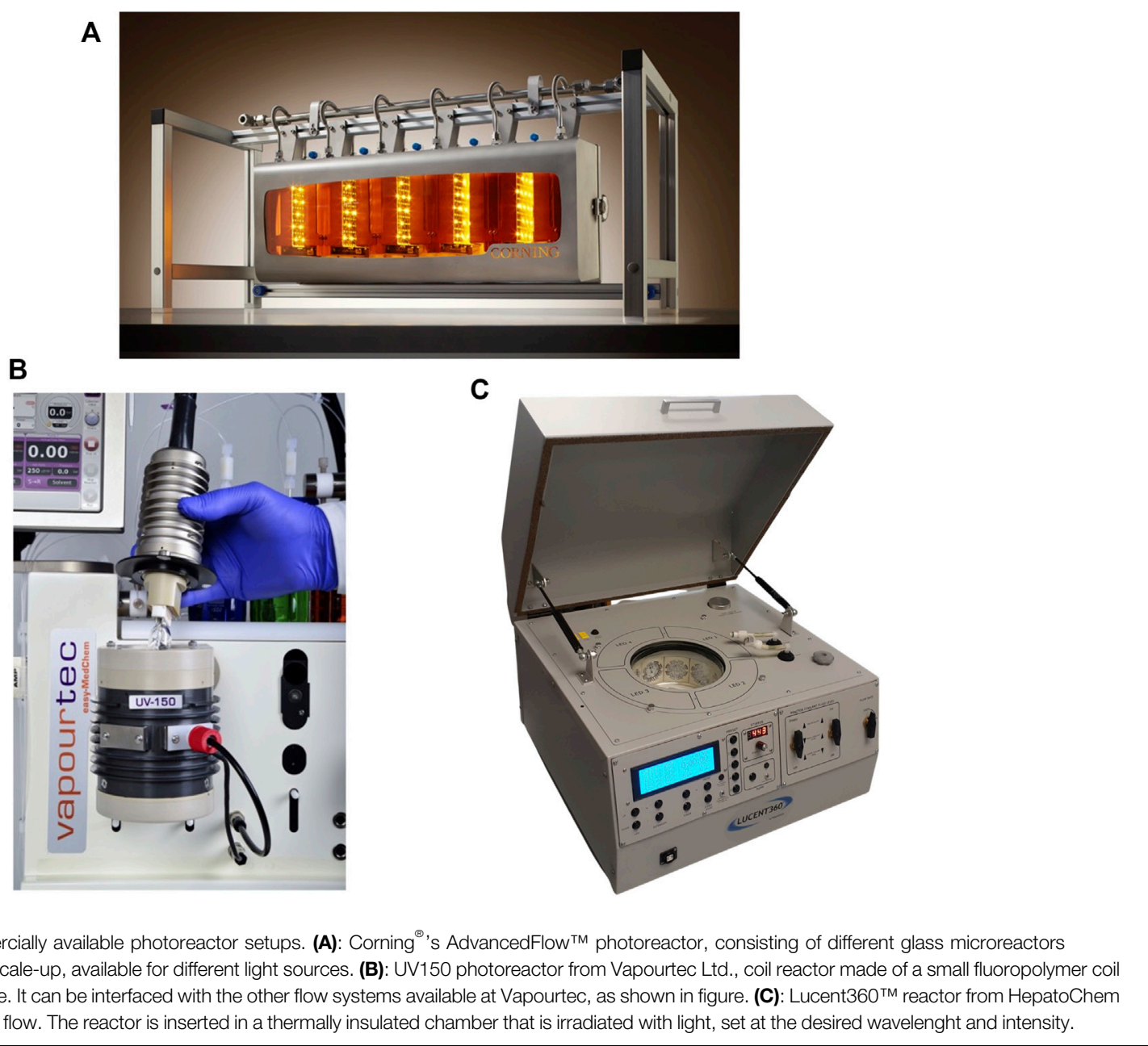

structure of CNDs and in the synthesis mechanisms of them, amongst others. Still, this is an exciting technology that in the future could be coupled with a biocatalyst to perform a process in continuous flow.

Finally, the specific activity is also a very significant parameter for process optimization. This is generally used in biocatalysis not only to consider the conversion of the starting material, but also to correlate it to the amount of biocatalyst used. Therefore, a compromise needs to be reached between the amount of biocatalyst used to save resources and to achieve a significant production rate. The specific activity can also be improved by means of protein engineering, as shown by the recent advances in the field (Schmermund et al., 2019; Seel and Gulder, 2019).

To assist the process design, many lab-scale photoreactors are commercially available from various suppliers, for example, Advanced-Flow ${ }^{\mathrm{TM}}$ reactors from Corning Inc.; Photochemical reactor UV-150 from Vapourtec Ltd.; or the Lucent $360^{\mathrm{TM}}$ reactor from HepatoChem Inc., all shown in Figure 6. Even though these PBRs are not explicitly meant for photobiocatalysis, they could still be adapted as such. Reliable open-source systems are also available, for example the already mentioned platform from Winkler et al. (2021) but also the 3DP system realized by
Böse et al. (2021), which also allows for an easy exchange of reactor vessels and light sources. Since for open-source projects all files, parts and codes are available, these systems are easily adaptable to the process at hand. Moreover, due to the increase in knowledge about additive manufacturing, tailor-made photoreactors can be realized via $3 \mathrm{D}$ printing also for specific purposes (Capel et al., 2018; Maier et al., 2020). By combining 3D printed parts with low-cost microcontrollers and electronics, it is possible to realize customized and integrated processes, where some selected process parameters (e.g., concentration, temperature and light intensity) can be controlled and investigated (Valotta et al., 2021). The compatibility of 3D printed parts and biocatalysts has already been proved in literature (Peris et al., 2017; Ye et al., 2019), but still to this day remains an open, non-explored possibility for photobiocatalysis. For the reader that wants to delve deeper into illumination advances and reactor design, we also recommend the review by Williams and Kappe (2020), dealing with advances in the field of flow photochemistry.

As a closing remark, it is relevant to mention the advances made with mathematical simulations, which can also help to better understand the influence of different parameters on the 
reactor, leading to the design of better PBRs and control systems. Regarding this subject it is worth noticing the very recent work by Skoneczny et al. (2021), who have formulated a mathematical model of a continuous-flow PBR and could investigate the influence of the dilution rate, incident irradiance, influent nitrogen concentration and bioreactor thickness on its steadystate properties for the synthesis of neutral lipids. Also (Borella et al., 2021), have retrieved kinetic growth parameters from a culture of the cyanobacterium Arthrospira maxima under a red/ blue LED light using increasing light intensities, and implemented them on a mathematical model, which was able to acceptably reproduce the experimental data. Based on their simulations, they were able to increase the biomass productivity around $15 \%$ by adjusting the residence time. Even though the productivity using the colored LEDs was comparable to that obtained using a white LED, the photosynthetic efficiency was much higher, with values up to $33.42 \pm 1.58 \%$, which results in a much more energy-saving process.

\section{Scale-Up}

Unlike typical thermal reactions, for photo(bio)catalytic reactions scale-up in the common sense of enlarging the reactor size (e.g., diameter/length) is rather limited due to the decreasing penetration depth of light in the reactor with increasing distance from the light source. In fact, it could be possible to switch from microreactors (ID $<1 \mathrm{~mm}$ ) to mesoreactors (ID > $1 \mathrm{~mm}$ ), however further optimization of the process parameters is needed, since the yield of the reaction is not directly scalable with the channel diameter. Three other possibilities are available to generate larger amounts of products: 1) running the process longer, or so-called "scale-out approach"; 2) increasing the flowrate or the length of the reactor, and 3) using multiple units in parallel, also called numbering-up (Anderson, 2012; Sambiagio and Noël, 2020). Scaling out is probably the easiest approach, as no further optimization of the process conditions is required. However, it is not an option in case the catalyst or other species involved prone to photodegradation over time (Sambiagio and Noël, 2020). The second option is similar to the first, however further optimization is needed since changing the flowrate means changing the flow behavior inside the reactor, which might negatively affect yield. Moreover, increasing the flowrate or the reactor length could also result in higher pressure drop in the system. The third option can be distinguished in external and internal numbering up: the first refers to using multiple separate units in parallel, the second to increasing the number of channels inside one reactor. This strategy is quite convenient, since the channel size is left unchanged and therefore the reaction outcome and flow behavior are unaffected. However, it is crucial to design an appropriate fluid delivery system to avoid flow maldistributions that might affect the residence time in the reaction unit (Saber et al., 2010) and reduce the overall performance of the system.

\section{When to Go Flow?}

Despite the many enumerated advantages of continuous processes, the possibility of bringing a biotransformation from batch to flow needs to be assessed on a case-to-case basis.
In general, for kinetic screening purposes, it is still recommendable to start from batch, especially in biocatalysis where the activity assay methods are well established and the reactions can be quickly screened in 96-well plates or small vials. However, if the final goal is to increase productivity, going flow is definitely worth considering (Valera et al., 2010; Hartman et al., 2011).

The main advantage of flow reactors compared to traditional batch reactors is indeed the higher surface area, due to their smaller characteristic dimensions (Su et al., 2014). As a result, the distances for the compounds to diffuse in the reaction solution are shorter and therefore mass transfer is enhanced, meaning that a better mixing can be obtained. This is particularly interesting for very fast and mixing-limited reactions, since the formation of local concentration gradients and consequently byproducts is prevented, resulting in a higher yield (Cambie et al., 2016). It is also advantageous in case of multiphase reactions because higher interfacial contact, and therefore higher transport rates can be achieved (Plutschack et al., 2017). Most importantly, in the specific case of photochemical reactions, the higher surface area and smaller inner dimensions in flow reactors can increase the light penetration and improve the light distribution, due to the reduced light diffusion path from the light source. This is a major asset of flow reactors, as shown in Figure 3. The light intensity can vary much more drastically within a flask, causing dark zones to be formed which can lower the overall reaction yield (Cambie et al., 2016). Moreover, the light exposure time can be precisely controlled by adjusting the flow rate and reactor volume, which can be particularly advantageous to avoid over-irradiation degradation of the catalyst or the compounds involved in the reaction (Knowles et al., 2012).

Improved heat transfer is another advantage that comes with the flow reactor geometry. Even though temperature is not the driving force of photochemical reactions, it is still important to keep the photoreactor at a constant and controlled temperature, especially for thermally unstable biocatalysts. Therefore, fast heat exchange is needed to compensate the possible heat dissipation of the light source (Cambie et al., 2016).

However, there are some limitations to continuous applications. Solid handling has been often appointed as an issue for the implementation of continuous equipment, but a discernment between different cases needs to be addressed. For reactions involving the precipitation of one of more species, or in the case that one or more reagents are in suspension due to solubility limits, the clogging of the reactor channels or other reaction equipment (e.g., mixers and pressure regulators) is highly likely, therefore batch reactors would be preferable (Plutschack et al., 2017). Inline filters are available and could be used to clarify the incoming stream before entering the reactor, however filter cleaning and exchange after a certain operating time needs to be planned into the operating procedure. Nonetheless, in case the (photo)biocatalyst is immobilized on solid carriers, continuous reactors such as packed beds can be more advantageous as higher biocatalyst loadings can be achieved and thus the reaction time can be decreased, thereby improving the overall process efficiency (Zhu et al., 2020). 
Another limitation from continuous flow arises when dealing with a slow reaction which is kinetics-limited. In fact, if the mixing or mass transport rate have little effect on the kinetics, it might still be more convenient to stay in batch. The same applies if the reaction is already reported to be satisfactory in batch with regards to yield, scale, and reaction time. Nevertheless, it should be considered that when dealing with a photobiocatalytic system, the improved light distribution that flow systems provide might result in a more efficient reaction. (Plutschack et al., 2017).

\section{CONCLUSION AND OUTLOOK}

Taking into account the urgent need of the world of heading towards a sustainable circular economy, bluntly evidenced by the latest UN report regarding global warming (IPCC, 2021), it is clear that a change is mandatory in the way we produce and manufacture goods, and chemical processes are not an exception.

In this context, the combination of biocatalysis and continuous flow chemistry has already given good results, increasing the efficiency and productivity of several processes thanks to some of its great characteristics, such as an excellent temperature control, high surface to volume ratio, and good mass transfer, amongst others. These features result in higher productivities, a better use of the available resources and the possibility of working under milder conditions, which ends up being much more environmentally advantageous when compared to classical strategies. Although the application of continuous flow in photobiocatalysis is a discipline that it is still taking its first steps, it already caused a great sensation in the community, with several articles proposing it as a solution for some of the challenges that photobiocatalysis entails (Schmermund et al., 2019; Meyer et al., 2021; Özgen et al., 2021).

We believe that the future studies on flow photobiocatalysis will be dedicated to the design of more efficient reactors. The greatest challenge is still to develop new technologies for a better light provision, which should include the optimization of low-impact light sources and transparent materials to increase the quantum yield. Another issue is the photobiocatalyst lifetime, however, with the recent

\section{REFERENCES}

Adessi, A., and De Philippis, R. (2014). Photobioreactor Design and Illumination Systems for H2 Production with Anoxygenic Photosynthetic Bacteria: A Review. Int. J. Hydrogen Energ. 39 (7), 3127-3141. doi:10.1016/ j.ijhydene.2013.12.084

Anderson, N. G. (2012). Using Continuous Processes to Increase Production. Org. Process. Res. Dev. 16 (5), 852-869. doi:10.1021/op200347k

Assil-Companioni, L., Büchsenschütz, H. C., Solymosi, D., Dyczmons-Nowaczyk, N. G., Bauer, K. K. F., Wallner, S., et al. (2020). Engineering of NADPH Supply Boosts Photosynthesis-Driven Biotransformations. ACS Catal. 10 (20), 11864-11877. doi:10.1021/acscatal.0c02601

Baer, S., Heining, M., Schwerna, P., Buchholz, R., and Hübner, H. (2016). Optimization of Spectral Light Quality for Growth and Product Formation in Different Microalgae Using a Continuous Photobioreactor. Algal Res. 14, 109-115. doi:10.1016/j.algal.2016.01.011 progresses in protein engineering more active and stable biocatalysts can be designed, which may also make the implementation of continuous photobioreactors in industry more feasible. In addition, immobilization strategies have made great improvements in the past years, which might open the possibility of increasing the biocatalyst reusability also for photocatalytic applications. Moreover, we believe that a great amount of the knowledge gathered in the recent years in the fields of chemical engineering, especially in additive manufacturing and inline analytics, will be applied to photobiocatalysis, to realize flexible and fully integrated flow photobioprocesses, for a greener and more efficient production of fine chemicals.

In this review, we provide a concise overview on the very latest advances on the field of flow photobiocatalysis, and of the photoreactor design principles, with the belief that these applications of flow technology hold a great potential for their widespread use in the near future.

\section{AUTHOR CONTRIBUTIONS}

SNC, AV, HG-W, and SK prepared, revised and were involved in the final editing of this review. All the authors approved the final submitted version.

\section{FUNDING}

This research was funded by Novo Nordisk Foundation LightBioFuels project, grant No NNF19OC0057522.

\section{ACKNOWLEDGMENTS}

SK and SNC wish to thank Novo Nordisk Foundation for the financial support. AV and HG-W also acknowledge the funding by the CATALOX (CATalytic mechanisms and AppLications of OXidoreductases) project, doc.fund program funded by the Austrian Science Fund (FWF).

Barber, J. (2016). 'Photosystem II: the Water Splitting Enzyme of Photosynthesis and the Origin of Oxygen in Our Atmosphere'. Q. Rev. Biophys. 49, e14. doi:10.1017/S0033583516000093

Björn, L. O. (2018). Photoenzymes and Related Topics: an Update. Photochem. Photobiol. 94 (3), 459-465. doi:10.1111/php.12892

Bolatkhan, K., Kossalbayev, B. D., Zayadan, B. K., Tomo, T., Veziroglu, T. N., and Allakhverdiev, S. I. (2019). Hydrogen Production from Phototrophic Microorganisms: Reality and Perspectives. Int. J. Hydrogen Energ. 44 (12), 5799-5811. doi:10.1016/j.ijhydene.2019.01.092

Bolivar, J. M., Wiesbauer, J., and Nidetzky, B. (2011). Biotransformations in Microstructured Reactors: More Than Flowing with the Stream? Trends Biotechnol. 29 (7), 333-342. doi:10.1016/j.tibtech.2011.03.005

Borella, L., Ortolan, D., Barbera, E., Trivellin, N., and Sforza, E. (2021). A Multiwavelength Model to Improve Microalgal Productivity and Energetic Conversion in a Red-Blue Light Emitting Diodes (LEDs) Continuous Photobioreactor. Energ. Convers. Management 243, 114330. doi:10.1016/ j.enconman.2021.114330 
Britton, J., Majumdar, S., and Weiss, G. A. (2018). Continuous Flow Biocatalysis. Chem. Soc. Rev. 47 (15), 5891-5918. doi:10.1039/c7cs00906b

Buglioni, L., Raymenants, F., Slattery, A., Zondag, S. D. A., and Noël, T. (2021). Technological Innovations in Photochemistry for Organic Synthesis: Flow Chemistry, High-Throughput Experimentation, Scale-Up, and Photoelectrochemistry. Chem. Rev. 1, 1. doi:10.1021/acs.chemrev.1c00332

Cambié, D., Bottecchia, C., Straathof, N. J. W., Hessel, V., and Noël, T. (2016). Applications of Continuous-Flow Photochemistry in Organic Synthesis, Material Science, and Water Treatment. Chem. Rev. 116 (17), 10276-10341. doi:10.1021/acs.chemrev.5b00707

Capel, A. J., Rimington, R. P., Lewis, M. P., and Christie, S. D. R. (2018). 3D Printing for Chemical, Pharmaceutical and Biological Applications. Nat. Rev. Chem. 2 (12), 422-436. doi:10.1038/s41570-018-0058-y

Chanquia, S. N., Huang, L., García Liñares, G., Domínguez de María, P., and Kara, S. (2020). Deep Eutectic Solvents as Smart Cosubstrate in Alcohol Dehydrogenase-Catalyzed Reductions. Catalysts 10 (9), 1013. doi:10.3390/ catal10091013

Chanquia, S. N., Vernet, G., and Kara, S. (2021). Photobioreactors for Cultivation and Synthesis: Specifications, Challenges, and Perspectives. Eng. Life Sci. 00, 1-11. doi:10.1002/elsc.202100070

Chisti, Y. (2007). Biodiesel from microalgae. Biotechnology advances 25 (3), 294-306. doi:10.1016/j.biotechadv.2007.02.001

Chitnis, P. R. (2001). Photosystem I: function and physiology. Annu. Rev. Plant. Physiol. Plant. Mol. Biol. 52 (1), 593-626. doi:10.1146/annurev.arplant.52.1.593

Choudhary, P., Prajapati, S. K., and Malik, A. (2016). Screening native microalgal consortia for biomass production and nutrient removal from rural wastewaters for bioenergy applications. Ecological Engineering 91, 221-230. doi:10.1016/ j.ecoleng.2015.11.056

Dasan, Y. K., Lam, M. K., Yusup, S., Lim, J. W., Show, P. L., Tan, I. S., and Lee, K. T. (2020). Cultivation of Chlorella vulgaris using sequential-flow bubble column photobioreactor: A stress-Inducing Strategy for Lipid Accumulation and Carbon Dioxide Fixation. J. CO2 Utilization 41, 101226. doi:10.1016/ j.jcou.2020.101226

de Bellefon, C. (2004). Chemical Micro-process Engineering. Fundamentals, Modelling and Reactions. By Volker Hessel, Steffen Hardt and Holger LöweFundamentals, Modelling and Reactions. By Volker Hessel, Steffen Hardt and Holger Löwe. Angew. Chem. Int. Edition 43 (48), 6583-6584. doi:10.1002/anie.200485187

De Santis, P., Meyer, L.-E., and Kara, S. (2020). The Rise of Continuous Flow Biocatalysis - Fundamentals, Very Recent Developments and Future Perspectives. React. Chem. Eng. 5 (12), 2155-2184. doi:10.1039/d0re00335b

Fabry, D. C., Sugiono, E., and Rueping, M. (2014). Self-Optimizing Reactor Systems: Algorithms, On-Line Analytics, Setups, and Strategies for Accelerating Continuous Flow Process Optimization. Isr. J. Chem. 54 (4), 341-350. doi:10.1002/ijch.201300080

Fabry, D. C., Sugiono, E., and Rueping, M. (2016). Online Monitoring and Analysis for Autonomous Continuous Flow Self-Optimizing Reactor Systems. React. Chem. Eng. 1 (2), 129-133. doi:10.1039/c5re00038f

Fernandes, B. D., Mota, A., Teixeira, J. A., and Vicente, A. A. (2015). Continuous Cultivation of Photosynthetic Microorganisms: Approaches, Applications and Future Trends. Biotechnol. Adv. 33 (6), 1228-1245. doi:10.1016/ j.biotechadv.2015.03.004

Geyer, K., Codée, J. D. C., and Seeberger, P. H. (2006). Microreactors as Tools for Synthetic Chemists-The Chemists' Round-Bottomed Flask of the 21st Century? Chem. Eur. J. 12 (33), 8434-8442. doi:10.1002/chem.200600596

Gkantzou, E., Patila, M., and Stamatis, H. (2018). Magnetic Microreactors with Immobilized Enzymes-From Assemblage to Contemporary Applications. Catalysts 8 (7), 282. doi:10.3390/catal8070282

Grogan, G. J., Bonfield, H., Mercer, K., Diaz-Rodriguez, A., Cook, G., McKay, B., et al. (2019). The Right Light-De Novo Design of a Robust Modular Photochemical Reactor for Optimum Batch and Flow Chemistry. ChemPhotoChem. 4, 45. doi:10.1002/cptc.201900203

Gu, F., Wang, Y., Meng, Z., Liu, W., and Qiu, L. (2020). A Coupled Photocatalytic/ enzymatic System for Sustainable Conversion of $\mathrm{CO} 2$ to Formate. Catal. Commun. 136, 105903. doi:10.1016/j.catcom.2019.105903

Gürsel, I. V., Noël, T., Wang, Q., and Hessel, V. (2015). Separation/recycling Methods for Homogeneous Transition Metal Catalysts in Continuous Flow. Green. Chem. 17 (4), 2012-2026. doi:10.1039/C4GC02160F
Gutmann, B., Cantillo, D., and Kappe, C. O. (2015). Continuous-Flow TechnologyA Tool for the Safe Manufacturing of Active Pharmaceutical Ingredients. Angew. Chem. Int. Ed. 54 (23), 6688-6728. doi:10.1002/anie.201409318

Hartman, R. L., McMullen, J. P., and Jensen, K. F. (2011). Deciding whether to Go with the Flow: Evaluating the Merits of Flow Reactors for Synthesis. Angew. Chem. Int. Ed. 50 (33), 7502-7519. doi:10.1002/anie.201004637

Heining, M., Sutor, A., Stute, S. C., Lindenberger, C. P., and Buchholz, R. (2015). Internal Illumination of Photobioreactors via Wireless Light Emitters: a Proof of Concept. J. Appl. Phycol 27 (1), 59-66. doi:10.1007/s10811-014-0290-x

Hessel, V., Löwe, H., and Schönfeld, F. (2005). Micromixers-a Review on Passive and Active Mixing Principles. Chem. Eng. Sci. 60 (8), 2479-2501. doi:10.1016/ j.ces.2004.11.033

Hobisch, M., Spasic, J., Malihan-Yap, L., Barone, G. D., Castiglione, K., Tamagnini, P., et al. (2021). Internal Illumination to Overcome the Cell Density Limitation in the Scale-Up of Whole-Cell Photobiocatalysis. ChemSusChem 14 (1-8), 3219-3225. doi:10.1002/cssc.202100832

Hollmann, F., Arends, I. W. C. E., and Buehler, K. (2010). Biocatalytic Redox Reactions for Organic Synthesis: Nonconventional Regeneration Methods. ChemCatChem 2 (7), 762-782. doi:10.1002/cctc.201000069

Hong, B.-C. (2020). Enantioselective Synthesis Enabled by Visible Light Photocatalysis. Org. Biomol. Chem. 18 (23), 4298-4353. doi:10.1039/ d0ob00759e

Hopkinson, M. N., Tlahuext-Aca, A., and Glorius, F. (2016). Merging Visible Light Photoredox and Gold Catalysis. Acc. Chem. Res. 49 (10), 2261-2272. doi:10.1021/acs.accounts.6b00351

Hoschek, A., Heuschkel, I., Schmid, A., Bühler, B., Karande, R., and Bühler, K. (2019). Mixed-species Biofilms for High-Cell-Density Application of Synechocystis Sp. PCC 6803 in Capillary Reactors for Continuous Cyclohexane Oxidation to Cyclohexanol. Bioresour. Technol. 282, 171-178. doi:10.1016/j.biortech.2019.02.093

Huijbers, M. M. E., Zhang, W., Tonin, F., and Hollmann, F. (2018). Light-Driven Enzymatic Decarboxylation of Fatty Acids. Angew. Chem. Int. Ed. 57 (41), 13648-13651. doi:10.1002/anie.201807119

Hutton, G. A. M., Martindale, B. C. M., and Reisner, E. (2017). Carbon Dots as Photosensitisers for Solar-Driven Catalysis. Chem. Soc. Rev. 46 (20), 6111-6123. doi: $10.1039 / \mathrm{c} 7 \mathrm{cs} 00235 \mathrm{a}$

IPCC (2021). Sixth Assessment Report (Switzerland: IPCC). Available at: https:// www.ipcc.ch/report/ar6/wg1/.

Jiang, D., Ge, X., Lin, L., Zhang, T., Liu, H., Hu, J., et al. (2020). Continuous PhotoFermentative Hydrogen Production in a Tubular Photobioreactor Using Corn Stalk Pith Hydrolysate with a Consortium. Int. J. Hydrogen Energ. 45 (6), 3776-3784. doi:10.1016/j.ijhydene.2019.06.078

Jung, S.-C., Kim, S.-J., Imaishi, N., and Cho, Y.-I. (2005). Effect of TiO2 Thin Film Thickness and Specific Surface Area by Low-Pressure Metal-Organic Chemical Vapor Deposition on Photocatalytic Activities. Appl. Catal. B: Environ. 55 (4), 253-257. doi:10.1016/j.apcatb.2004.08.009

Kashid, M. N., Renken, A., and Kiwi-Minsker, L. (2011). Gas-liquid and LiquidLiquid Mass Transfer in Microstructured Reactors. Chem. Eng. Sci. 66 (17), 3876-3897. doi:10.1016/j.ces.2011.05.015

Kayahan, E., Eroglu, I., and Koku, H. (2017). A Compact Tubular Photobioreactor for Outdoor Hydrogen Production from Molasses. Int. J. Hydrogen Energ. 42 (4), 2575-2582. doi:10.1016/j.ijhydene.2016.08.014

Kim, D., and Herr, A. E. (2013). Protein Immobilization Techniques for Microfluidic Assays. Biomicrofluidics 7 (4), 41501. doi:10.1063/1.4816934

Knowles, J. P., Elliott, L. D., and Booker-Milburn, K. I. (2012). Flow Photochemistry: Old Light through New Windows. Beilstein J. Org. Chem. 8 (1), 2025-2052. doi:10.3762/bjoc.8.229

Köninger, K., Baraibar, Á. Gómez., Mügge, C., Paul, C. E., Hollmann, F., Nowaczyk, M. M., et al. (2016). RecombinantCyanobacteria for the Asymmetric Reduction of $\mathrm{C}=\mathrm{C}$ Bonds Fueled by the Biocatalytic Oxidation of Water. Angew. Chem. Int. Edition 55 (18), 5582-5585.

Kockmann, N., Kiefer, T., Engler, M., and Woias, P. (2006). Convective Mixing and Chemical Reactions in Microchannels with High Flow Rates. Sensors Actuators B: Chem. 117 (2), 495-508. doi:10.1016/j.snb.2006.01.004

Lakavath, B., Hedison, T. M., Heyes, D. J., Shanmugam, M., Sakuma, M., Hoeven, R., et al. (2020). Radical-based Photoinactivation of Fatty Acid Photodecarboxylases. Anal. Biochem. 600, 113749. doi:10.1016/ j.ab.2020.113749 
Lee, J.-C., Baek, K., and Kim, H.-W. (2018a). Semi-continuous Operation and Fouling Characteristics of Submerged Membrane Photobioreactor (SMPBR) for Tertiary Treatment of Livestock Wastewater. J. Clean. Prod. 180, 244-251. doi:10.1016/j.jclepro.2018.01.159

Lee, S. H., Choi, D. S., Kuk, S. K., and Park, C. B. (2018b). Photobiocatalysis: Activating Redox Enzymes by Direct or Indirect Transfer of Photoinduced Electrons. Angew. Chem. Int. Ed. 57 (27), 7958-7985. doi:10.1002/ anie. 201710070

Ley, S. V., Fitzpatrick, D. E., Ingham, R. J., and Myers, R. M. (2015). Organic Synthesis: March of the Machines. Angew. Chem. Int. Ed. 54 (11), 3449-3464. doi:10.1002/anie.201410744

Liu, X., Zhao, Y., Yang, X., Liu, Q., Yu, X., Li, Y., et al. (2020). Porous Ni5P4 as a Promising Cocatalyst for Boosting the Photocatalytic Hydrogen Evolution Reaction Performance. Appl. Catal. B: Environ. 275, 119144. doi:10.1016/ j.apcatb.2020.119144

López-Vidal, M. G., Gamboa, G., Oksdath-Mansilla, G., and Bisogno, F. R. (2021). Photobiocatalysis. Biocatalysis for Practitioners. Wiley, 317-359.

Loubière, K., Oelgemöller, M., Aillet, T., Dechy-Cabaret, O., and Prat, L. (2016). Continuous-flow Photochemistry: A Need for Chemical Engineering. Chem. Eng. Process. Process Intensification 104, 120-132. doi:10.1016/ j.cep.2016.02.008

Maciá Agulló, J. A., Corma Canós, A., and García Gómez, H. (2015). Photobiocatalysis: the Power of Combining Photocatalysis and Enzymes. Chemistry-a Eur. J. 21 (31), 10940-10959.

Maier, M. C., Valotta, A., Hiebler, K., Soritz, S., Gavric, K., Grabner, B., et al. (2020). 3D Printed Reactors for Synthesis of Active Pharmaceutical Ingredients in Continuous Flow. Org. Process. Res. Dev. 24 (10), 2197-2207. doi:10.1021/ acs.oprd.0c00228

Mallia, C. J., and Baxendale, I. R. (2016). The Use of Gases in Flow Synthesis. Org. Process. Res. Dev. 20 (2), 327-360. doi:10.1021/acs.oprd.5b00222

Mathur, A. K., and Balomajumder, C. (2013). Biological Treatment and Modeling Aspect of BTEX Abatement Process in a Biofilter. Bioresour. Technology 142, 9-17. doi:10.1016/j.biortech.2013.05.005

Meng, A., Zhang, L., Cheng, B., and Yu, J. (2019). Dual Cocatalysts in TiO 2 Photocatalysis. Adv. Mater. 31 (30), 1807660. doi:10.1002/adma.201807660

Meyer, L.-E., Eser, B. E., and Kara, S. (2021). Coupling Light with Biocatalysis for Sustainable Synthesis-Very Recent Developments and Future Perspectives. Curr. Opin. Green Sustainable Chem. 31, 100496. doi:10.1016/ j.cogsc.2021.100496

Mudliar, S., Giri, B., Padoley, K., Satpute, D., Dixit, R., Bhatt, P., et al. (2010). Bioreactors for Treatment of VOCs and Odours - A Review. J. Environ. Manage. 91 (5), 1039-1054. doi:10.1016/j.jenvman.2010.01.006

Muradov, N. (2017). Low to Near-Zero CO2 Production of Hydrogen from Fossil Fuels: Status and Perspectives. Int. J. Hydrogen Energ. 42 (20), 14058-14088. doi:10.1016/j.ijhydene.2017.04.101

Noël, T., and Hessel, V. (2013). Membrane Microreactors: Gas-Liquid Reactions Made Easy. ChemSusChem 6 (3), 405-407. doi:10.1002/cssc.201200913

Oliva, G., Ángeles, R., Rodríguez, E., Turiel, S., Naddeo, V., Zarra, T., et al. (2019). Comparative Evaluation of a Biotrickling Filter and a Tubular Photobioreactor for the Continuous Abatement of Toluene. J. Hazard. Mater. 380, 120860. doi:10.1016/j.jhazmat.2019.120860

Özgen, F. F., Runda, M. E., and Schmidt, A. P. S. (2021). Photo-biocatalytic Cascades: Combining Chemical and Enzymatic Transformations Fueled by Light. ChemBioChem 22 (5), 790. doi:10.1002/cbic.202000587

Pastre, J. C., Browne, D. L., and Ley, S. V. (2013). Flow Chemistry Syntheses of Natural Products. Chem. Soc. Rev. 42 (23), 8849-8869. doi:10.1039/c3cs60246j

Peris, E., Okafor, O., Kulcinskaja, E., Goodridge, R., Luis, S. V., Garcia-Verdugo, E., et al. (2017). Tuneable 3D Printed Bioreactors for Transaminations under Continuous-Flow. Green. Chem. 19 (22), 5345-5349. doi:10.1039/c7gc02421e

Plutschack, M. B., Pieber, B., Gilmore, K., and Seeberger, P. H. (2017). The Hitchhiker's Guide to Flow Chemistryll. Chem. Rev. 117 (18), 11796-11893. doi:10.1021/acs.chemrev.7b00183

Remmers, I. M., Hidalgo-Ulloa, A., Brandt, B. P., Evers, W. A. C., Wijffels, R. H., and Lamers, P. P. (2017). Continuous versus Batch Production of Lipids in the Microalgae Acutodesmus Obliquus. Bioresour. Technol. 244, 1384-1392. doi:10.1016/j.biortech.2017.04.093

Rokhmat, M., Wibowo, E., and Abdullah, M. (2017). Prototype of a Flat-Panel Photoreactor Using TiO2 Nanoparticles Coated on Transparent Granules for the Degradation of Methylene Blue under Solar Illumination. Sustainable Environ. Res. 27 (4), 172-180. doi:10.1016/j.serj.2017.04.002

Sánchez-Contreras, M. I., Morales-Arrieta, S., Okoye, P. U., Guillén-Garcés, R. A., Sebastian, P., and Arias, D. M. (2021). Recycling Industrial Wastewater for Improved Carbohydrate-Rich Biomass Production in a Semi-continuous Photobioreactor: Effect of Hydraulic Retention Time. J. Environ. Manage. 284,112065 .

Sánchez-Morales, M., Sabater, F., and Muñoz, I. (2018). Effects of Urban Wastewater on Hyporheic Habitat and Invertebrates in Mediterranean Streams. Sci. Total Environ. 642, 937-945.

Saber, M., Commenge, J. M., and Falk, L. (2010). Microreactor Numbering-Up in Multi-Scale Networks for Industrial-Scale Applications: Impact of Flow Maldistribution on the Reactor Performances. Chem. Eng. Sci. 65 (1), 372-379. doi:10.1016/j.ces.2009.06.010

Sağır, E., Yucel, M., and Hallenbeck, P. C. (2018). Demonstration and Optimization of Sequential Microaerobic Dark- and Photo-Fermentation Biohydrogen Production by Immobilized Rhodobacter Capsulatus JP91. Bioresour. Technol. 250, 43-52. doi:10.1016/j.biortech.2017.11.018

Sambiagio, C., and Noël, T. (2020). Flow Photochemistry: Shine Some Light on Those Tubes!. Trends Chem. 2 (2), 92-106. doi:10.1016/j.trechm.2019.09.003

Sancar, A. (2003). Structure and Function of DNA Photolyase and Cryptochrome Blue-Light Photoreceptors. Chem. Rev. 103 (6), 2203-2238. doi:10.1021/ cr0204348

Sancar, A. (2016). Mechanisms of DNA Repair by Photolyase and Excision Nuclease (Nobel Lecture). Angew. Chem. Int. Ed. 55 (30), 8502-8527. doi:10.1002/anie.201601524

Santner, P., Szabó, L. K., Chanquia, S. N., Merrild, A. H., Hollmann, F., Kara, S., et al. (2021). Optimization and Engineering of Fatty Acid Photodecarboxylase for Substrate Specificity. ChemCatChem. 17, 4038. doi:10.1002/cctc.202100840

Schiel, F., Peinsipp, C., Böse, S. D., and Schiel, F. (2021). A 3D-Printed Open Access Photoreactor Designed for Versatile Applications in Photoredox- and Photoelectrochemical Synthesis. ChemPhotoChem 5, 431-437. doi:10.1002/ cptc.202000291

Schmermund, L., Jurkaš, V., Özgen, F. F., Barone, G. D., Büchsenschütz, H. C., Winkler, C. K., et al. (2019). Photo-Biocatalysis: Biotransformations in the Presence of Light. ACS Catal. 9 (5), 4115-4144. doi:10.1021/acscatal.9b00656

Schmermund, L., Bierbaumer, S., Schein, V. K., Winkler, C. K., Kara, S., and Kroutil, W. (2020). Extending the Library of Light-Dependent Protochlorophyllide Oxidoreductases and Their Solvent Tolerance, Stability in Light and Cofactor Flexibility. ChemCatChem 12 (16), 4044-4051. doi:10.1002/cctc.202000561

Schoefs, B., and Franck, F. (2003). Protochlorophyllide Reduction: Mechanisms and Evolutiong. Photochem. Photobiol. 78 (6), 543-557. doi:10.1562/00318655(2003)078<0543:prmae >2.0.co;2

Scrutton, N. S. (2017). Enzymes Make Light Work of Hydrocarbon Production. Science 357 (6354), 872-873. doi:10.1126/science.aao4399

Seel, C. J., and Gulder, T. (2019). Biocatalysis Fueled by Light: on the Versatile Combination of Photocatalysis and Enzymes. ChemBioChem 20 (15), 1871-1897. doi:10.1002/cbic.201800806

Sero, E. T., Siziba, N., Bunhu, T., Shoko, R., and Jonathan, E. (2020). Biophotonics for Improving Algal Photobioreactor Performance: A Review. Int. J. Energ. Res 44 (7), 5071-5092. doi:10.1002/er.5059

Skoneczny, S., Myszka, M., and Cioch-Skoneczny, M. (2021). Steady-state Characteristics of a Continuous-Flow Photobioreactor for Neutral Lipids Synthesis by Microalgae. Biomass and Bioenergy 148, 106049. doi:10.1016/j.biombioe.2021.106049

Sorigué, D., Légeret, B., Cuiné, S., Blangy, S., Moulin, S., Billon, E., et al. (2017). An Algal Photoenzyme Converts Fatty Acids to Hydrocarbons. Science 357 (6354), 903-907. doi:10.1126/science.aan6349

Su, Y., Straathof, N. J. W., Hessel, V., and Noël, T. (2014). Photochemical Transformations Accelerated in Continuous-Flow Reactors: Basic Concepts and Applications. Chem. Eur. J. 20 (34), 10562-10589. doi:10.1002/ chem. 201400283

Su, Y., Kuijpers, K., Hessel, V., and Noël, T. (2016). A Convenient Numbering-Up Strategy for the Scale-Up of Gas-Liquid Photoredox Catalysis in Flow. React. Chem. Eng. 1 (1), 73-81. doi:10.1039/c5re00021a

Sundar, K. P., and Kanmani, S. (2020). Progression of Photocatalytic Reactors and It's Comparison: A Review. Chem. Eng. Res. Des. 154, 135-150. doi:10.1016/ j.cherd.2019.11.035 
Talla, A., Driessen, B., Straathof, N. J., Milroy, L. G., Brunsveld, L., Hessel, V., et al. (2015). Metal-free Photocatalytic Aerobic Oxidation of Thiols to Disulfides in Batch and Continuous-flow. Adv. Synth. Catal. 357 (10), 2180-2186. doi:10.1002/adsc.201401010

Thompson, M. P., Peñafiel, I., Cosgrove, S. C., and Turner, N. J. (2018). Biocatalysis Using Immobilized Enzymes in Continuous Flow for the Synthesis of fine Chemicals. Org. Process Res. Development 23 (1), 9-18. doi:10.1021/ acs.oprd.8b00305

Tsygankov, A., and Kosourov, S. (2014). Immobilization of Photosynthetic Microorganisms for Efficient Hydrogen Production. Microb. BioEnergy: Hydrogen Prod. 1, 321-347. doi:10.1007/978-94-017-8554-9_14

Valera, F. E., Quaranta, M., Moran, A., Blacker, J., Armstrong, A., Cabral, J. T., and Blackmond, D. G. (2010). The Flow's the Thing. . or Is it? Assessing the Merits of Homogeneous Reactions in Flask and Flow. Angew. Chem. Int. Edition 49 (14), 2478-2485. doi:10.1002/anie.200906095

Valotta, A., Maier, M. C., Soritz, S., Pauritsch, M., Koenig, M., Brouczek, D., et al. (2021). 3D Printed Ceramics as Solid Supports for Enzyme Immobilization: an Automated DoE Approach for Applications in Continuous Flow. J. Flow Chem. 11, 675. doi:10.1007/s41981-021-00163-4

Vinyard, D. J., Ananyev, G. M., and Charles Dismukes, G. (2013). Photosystem II: the Reaction center of Oxygenic Photosynthesis. Annu. Rev. Biochem. 82, 577-606. doi:10.1146/annurev-biochem-070511-100425

Visan, A., van Ommen, J. R., Kreutzer, M. T., and Lammertink, R. G. H. (2019). Photocatalytic Reactor Design: Guidelines for Kinetic Investigation. Ind. Eng. Chem. Res. 58 (14), 5349-5357. doi:10.1021/ acs.iecr.9b00381

Vonshak, A., and Torzillo, G. (2004). "Environmental Stress Physiology," in Handbook of Microalgal Culture: Biotechnology and Applied Phycology. Editor A. Richmond (Wiley), 57. doi:10.1002/9780470995280

Wang, Y., Tahir, N., Cao, W., Zhang, Q., and Lee, D.-J. (2019). Grid Columnar Flat Panel Photobioreactor with Immobilized Photosynthetic Bacteria for Continuous Photofermentative Hydrogen Production. Bioresour. Technology 291, 121806. doi:10.1016/j.biortech.2019.121806

Webb, D., and Jamison, T. F. (2010). Continuous Flow Multi-step Organic Synthesis. Chem. Sci. 1 (6), 675-680. doi:10.1039/c0sc00381f

Wegner, J., Ceylan, S., and Kirschning, A. (2011). Ten Key Issues in Modern Flow Chemistry. Chem. Commun. 47 (16), 4583-4592. doi:10.1039/ c0cc05060a

Williams, J. D., and Kappe, C. O. (2020). Recent Advances toward Sustainable Flow Photochemistry. Curr. Opin. Green Sustainable Chem. 25, 100351. doi:10.1016/ j.cogsc.2020.05.001

Winkler, C., Simić, S., Jurkaš, V., Bierbaumer, S., Schmermund, L., Poschenrieder, S., et al. (2021). Accelerated Reaction Engineering of Photo (Bio) Catalytic Reactions through Parallelization with an OpenSource Photoreactor. ChemPhotoChem 5, 957. doi:10.1002/ cptc.202100109

Ye, J., Chu, T., Chu, J., Gao, B., and He, B. (2019). A Versatile Approach for Enzyme Immobilization Using Chemically Modified 3D-Printed Scaffolds. ACS Sustainable Chem. Eng. 7 (21), 18048-18054. doi:10.1021/ acssuschemeng.9b04980
Yen, H.-W., Hu, I.-C., Chen, C.-Y., Nagarajan, D., and Chang, J.-S. (2019). Design of Photobioreactors for Algal Cultivation. Biofuels from algae 1, 225-256. doi:10.1016/b978-0-444-64192-2.00010-x

Yoon, T. P., Ischay, M. A., and Du, J. (2010). Visible Light Photocatalysis as a Greener Approach to Photochemical Synthesis. Nat. Chem. 2 (7), 527-532. doi: $10.1038 /$ nchem. 687

Zhang, C., Zhu, X., Liao, Q., Wang, Y., Li, J., Ding, Y., et al. (2010). Performance of a Groove-type Photobioreactor for Hydrogen Production by Immobilized Photosynthetic Bacteria. Int. J. Hydrogen Energ. 35 (11), 5284-5292. doi:10.1016/ j.ijhydene.2010.03.085

Zhang, C., Ma, S., Wang, G., and Guo, Y. (2019). Enhancing Continuous Hydrogen Production by Photosynthetic Bacterial Biofilm Formation within an Alveolar Panel Photobioreactor. Int. J. Hydrogen Energ. 44 (50), 27248-27258. doi:10.1016/j.ijhydene.2019.08.183

Zheng, Q., Aiello, A., Choi, Y. S., Tarr, K., Shen, H., Durkin, D. P., et al. (2020). 3D Printed Photoreactor with Immobilized Graphitic Carbon Nitride: A Sustainable Platform for Solar Water Purification. J. Hazard. Mater. 399, 123097. doi:10.1016/j.jhazmat.2020.123097

Zhou, X., Yuan, S., Chen, R., and Ochieng, R. M. (2015). Sustainable Production of Energy from Microalgae: Review of Culturing Systems, Economics, and Modelling. J. Renew. Sustainable Energ. 7 (1). doi:10.1063/1.4906919

Zhu, Y., Jones, S. B., and Anderson, D. B. (2018). Algae Farm Cost Model: Considerations for Photobioreactors, Pacific Northwest National Lab. (PNNL). Richland, WA (United States): USDOE.

Zhu, Y., Chen, Q., Shao, L., Jia, Y., and Zhang, X. (2020). Microfluidic Immobilized Enzyme Reactors for Continuous Biocatalysis. React. Chem. Eng. 5 (1), 9-32. doi:10.1039/c9re00217k

Žnidaršič-Plazl, P. (2021a). Let the Biocatalyst Flow. Acta Chim. Slovenica 68 (1), 1-16.

Žnidaršič-Plazl, P. (2021b). Biocatalytic Process Intensification via Efficient Biocatalyst Immobilization, Miniaturization, and Process Integration. Curr. Opin. Green Sustainable Chem. 32, 100546. doi:10.1016/j.cogsc.2021.100546

Conflict of Interest: The authors declare that the research was conducted in the absence of any commercial or financial relationships that could be construed as a potential conflict of interest.

Publisher's Note: All claims expressed in this article are solely those of the authors and do not necessarily represent those of their affiliated organizations, or those of the publisher, the editors and the reviewers. Any product that may be evaluated in this article, or claim that may be made by its manufacturer, is not guaranteed or endorsed by the publisher.

Copyright (c) 2022 Chanquia, Valotta, Gruber-Woelfler and Kara. This is an openaccess article distributed under the terms of the Creative Commons Attribution License (CC BY). The use, distribution or reproduction in other forums is permitted, provided the original author(s) and the copyright owner(s) are credited and that the original publication in this journal is cited, in accordance with accepted academic practice. No use, distribution or reproduction is permitted which does not comply with these terms. 